
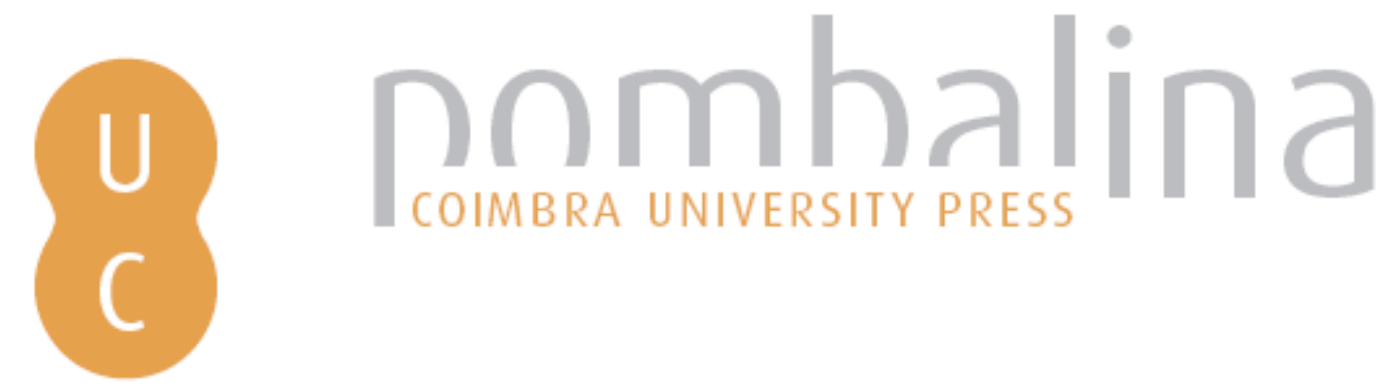

\title{
Relaciones del coro y de los componentes del espectáculo con la acción dramática en Una hoguera en las tinieblas de Médici e Iñiguez
}

Autor(es): $\quad$ Liñán, Alejandra Mabel; Viñote, Lucía Casal

Publicado por: Imprensa da Universidade de Coimbra

URL

persistente: URI:http://hdl.handle.net/10316.2/43002

DOI: $\quad$ DOl:https://doi.org/10.14195/978-989-26-1439-7_22

Accessed : $\quad$ 26-Apr-2023 09:20:24

A navegação consulta e descarregamento dos títulos inseridos nas Bibliotecas Digitais UC Digitalis, UC Pombalina e UC Impactum, pressupõem a aceitação plena e sem reservas dos Termos e Condições de Uso destas Bibliotecas Digitais, disponíveis em https://digitalis.uc.pt/pt-pt/termos.

Conforme exposto nos referidos Termos e Condições de Uso, o descarregamento de títulos de acesso restrito requer uma licença válida de autorização devendo o utilizador aceder ao(s) documento(s) a partir de um endereço de IP da instituição detentora da supramencionada licença.

Ao utilizador é apenas permitido o descarregamento para uso pessoal, pelo que o emprego do(s) título(s) descarregado(s) para outro fim, designadamente comercial, carece de autorização do respetivo autor ou editor da obra.

Na medida em que todas as obras da UC Digitalis se encontram protegidas pelo Código do Direito de Autor e Direitos Conexos e demais legislação aplicável, toda a cópia, parcial ou total, deste documento, nos casos em que é legalmente admitida, deverá conter ou fazer-se acompanhar por este aviso.

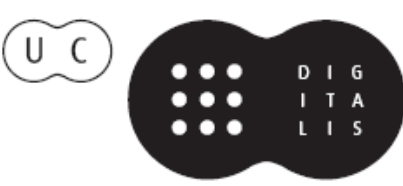




\section{Pervivencia del mundo clásico en la literatura:}

\section{tradición y relecturas}

\section{Aldo Rubén Pricco, Stella Maris Moro (coords.)}

IMPRENSA DA UNIVERSIDADE DE COIMBRA 


\title{
RELACIONES DEL CORO Y DE LOS COMPONENTES DEL ESPECTÁCULO CON LA ACCIÓN DRAMÁTICA EN UNA HOGUERA EN LAS TINIEBLAS DE MÉDici E IÑIgUEZ \\ (Relations between the chorus and other performance elements with the dramatic action in Una hoguera en las tinieblas by Médici and Iñiguez)
}

\author{
Alejandra Mabel Liñán (alejandralinan@yahoo.com.ar) \\ Facultad de Humanidades - U.N.N.E \\ Lucía Casal VIñote (casallucia@hotmail.com) \\ Facultad de Humanidades - U.N.N.E
}

\begin{abstract}
Resumen - La obra correntina inédita Una hoguera en las tinieblas, de Médici e Iñiguez, mantiene del hipotexto el género, el mito, los personajes y sus funciones, pero sitúa la acción en Corrientes, en 1817. A diferencia de la tragedia ática, en esta obra el coro tiene otro matiz: integrado por espíritus telúricos de la cultura guaraní, lleva adelante y desencadena la acción. Por el carácter sagrado que representan los espíritus, tiene una libertad que no tenía en el hipotexto. En este trabajo nos centraremos en la función dramática que desempeña el coro y en el tratamiento de los elementos escénicos (coreografía, música, iluminación y vestuario) que crean un halo sobrenatural sobre él.
\end{abstract}

Palabras Clave: Coro, hipotexto, elementos escénicos, recepción, Medea.

Aвstract - The unpublished work Una hoguera en las tinieblas by Médici \& Iñiguez maintains the hypotext gender, myth, characters and their functions, but sets the action in Corrientes, in 1817. Unlike Attic tragedy, the chorus has a different nuance: composed of telluric spirits of the Guarani culture, conducts and triggers the action. By the sacred character representing the spirits, this choir has a freedom that was not in the hypotext. This work will focus on the dramatic role of the chorus and the treatment of the scenic elements (choreography, music, lighting and costumes) to create a supernatural halo about it.

Keywords: Chorus, hipotext, scenic elements, reception, Medea.

El teatro clásico, con los rasgos propios de su cultura y de su práctica teatral, permanece vivo en la escena contemporánea, por medio de la apropiación y recreación en nuevas puestas que responden a las necesidades de otro contexto social y político. Hardwick ${ }^{1}$ sostiene que el drama antiguo es modelo y, a la vez, disparador para el teatro moderno.

El presente trabajo se inscribe en la línea de análisis de estudios de la

\footnotetext{
${ }^{1}$ Hardwick 2003:52.
} 
recepción de la tradición clásica y en la literatura comparada. Se analizará la tragedia inédita Una Hoguera en las Tinieblas (versión libre de Medea de Eurípides), escrita por Alberto Iñiguez y Julio Maccarone Médici y estrenada en 1987, con motivo del aniversario de la fundación de la Ciudad de San Juan de Vera de las Siete Corrientes, Argentina.

En esta tragedia se produce un horizonte de fusión con Medea de Eurípides. La pertenencia architextual ${ }^{2}$ puede evidenciarse en la persistencia del género, del esquema de los personajes, sus nombres y funciones y en la presencia de determinados componentes del espectáculo propios de la tragedia griega del siglo V a. C., tales como el coro, las máscaras y la danza.

Pretendemos analizar particularmente las relaciones del coro y los componentes del espectáculo con la acción dramática, a fin de describir la nueva mirada que los dramaturgos correntinos le imprimieron a través de tres lenguajes de la puesta en escena: sonido, vestuario e iluminación.

La representación se realizó 30 años atrás y no hay registro fílmico de ella; es así que abordaremos el análisis a partir del texto dramático (conservado en copia mecanografiada), de una entrevista, realizada el 4 de junio de 2011, a la actriz María Dolores Arigossi, quien encarnó a Medea, y de fuentes documentales, como el programa y algunas fotografías de la puesta en escena.

\section{RELACión ARCHITEXTUAL}

\section{Género y personajes (nombres y funciones)}

Una hoguera en las tinieblas fue estrenada en 1987 por la compañía del "Teatro Vocacional Corrientes" en el escenario principal de la ciudad, el Teatro Oficial Juan de Vera. Un equipo de destacados representantes de la cultura correntina trabajó para la producción y puesta en escena: Médici e Iñiguez escribieron la obra a pedido de la actriz María Dolores Arigossi, en dos meses, aproximadamente. E1 vestuario y las máscaras fueron diseñados por José Ramírez, la música fue compuesta por Romero Maciel y Miguel Fiorio diseñó la ilustración y el programa.

La obra correntina transpola el mito de Medea a los campos de San José de las Siete Lagunas Saladas, Corrientes, en 1817, durante el gobierno de Juan Manuel Méndez, hombre de Artigas y de Andresito Guaicurarí.

Medea es una princesa guaraní, que mató a su hermano y traicionó a su pueblo para ayudar a Jasón, un criollo, a apoderarse del lugar. Por estas acciones fue desterrada y ha vagado con su marido y sus dos hijos durante diez años, rechazados por ambas culturas, tal como lo afirma la vieja (correlato de la Nodriza en la tragedia de Eurípides) que acompañó a Medea en su destierro:

\footnotetext{
${ }^{2}$ Genette 1962: 13 .
} 
Vieja - (...) Despreciadas e ignoradas por los nuestros... odiadas por los blancos... ¡Qué largo es el camino... qué largo! ${ }^{3}$

Finalmente llegan a las ruinas de la casa paterna de Jasón, en Saladas. Allí, al igual que la Medea del hipotexto, es abandonada para que él pueda casarse con la hija de Creonte Atienza, su tío y caudillo de la zona.

Teniendo en cuenta la reputación de la que goza Medea por sus crímenes y por hacer payé, Creonte le comunica que debe irse de esas tierras en el plazo de una hora, pero puede dejar a sus hijos para que sean criados por su padre y su madrastra.

Luego de acordar refugio con el Oriental (correlato de Egeo en el hipotexto), con quien Medea se compromete a ayudar a su esposa a concebir un hijo por medio de magia, lleva adelante su venganza: mata a Creonte, a la hija y a sus propios hijos: "Medea: ¡Han muerto degollados!»

\section{Coro en relación con los componentes del espectáculo}

La tragedia correntina se inicia con la entrada de un coro de animales salvajes característicos de la región del noreste argentino: yaguateré, aguará y ñacurutú. Los integrantes del coro portan medias máscaras que identifican a cada animal: "El coro lleva jirones de tela rústica y follaje sobre el cuerpo desnudo y media máscara que representará animales salvajes del Litoral”.

El vestuario del coro (jirones de tela, follaje y medias máscaras) se modela sobre la base de elementos que remiten a la naturaleza local, pero cuyo sentido, a la vez, apunta a la cultura guaraní, ya que esos animales son divinidades ctónicas.

Aristóteles, en Poética 1452b 15-18, identifica cuatro partes externas en la tragedia: prólogo, episodio, éxodo y la parte coral, que a su vez se divide en párodo y estásimo. Médici e Iñiguez, en Una Hoguera en las Tinieblas, mantienen estas partes; en este trabajo, sólo nos centramos en aquellas en las que participa el coro, es decir, ambos momentos de la parte coral y el éxodo.

En la párodo, el coro de animales salvajes del litoral ingresa a escena cantando y danzando: "se escucha una música que recuerda a los sones tribales guaraníes, acompañada por una letanía cantada en guaraní por los integrantes del coro, quienes entrarán lentamente a escena". ${ }^{6} \mathrm{~A}$ la vez que evoca al coro de sátiros, la música acompañada por la letanía cantada hace recordar el canto monótono de la melopea.

El escenario está desprovisto de decorado; al ingresar los seis coreutas sólo hay una luz azulada y otra roja más débil que proviene de una pequeña fogata:

\footnotetext{
${ }^{3}$ Médici e Iñiguez 1987: 5.

${ }^{4}$ Médici e Iñiguez 1987: 31.

${ }^{5}$ Médici e Iñiguez 1987: 1.

${ }^{6}$ Médici e Iñiguez 1987: 1.
} 
Al comenzar la acción, está terminando de atardecer y ya comienza la noche, por lo que una luz azulada baña toda la escena. (...)

Un pequeño fuego, siempre a punto de apagarse, dará los tonos rojizos necesarios. Es el fuego familiar y tribal a la vez ${ }^{7}$.

En esta especie de párodo, la atención del espectador se focaliza en el coro, que permanecerá durante toda la representación en el escenario y actuará como decorado viviente detrás de los otros personajes, durante los agones:

El coro deberá actuar con movimientos danzados y formarán parte de una extraña escenografía viviente mientras queda estático ${ }^{8}$.

El coro se comporta como agente y como parte de la escenografía, al mismo tiempo. El carácter estático durante los episodios sugiere la participación en los estásimos, en forma similar a la tragedia ática: el adjetivo griego stasimos tiene el sentido de "estacionario", "sedentario", "parado". Sin embargo, adopta movimientos danzados en sus intervenciones. De este modo se mueve en un diseño coreográfico y constituye un decorado sonoro.

A modo de prólogo, los coreutas nos informan sobre los antecedentes de la historia:

Coro 2 - ¿Qué ves?

Coro 3 - ¡Ruinas!

Coro 3 - ¡Es lo que queda de la casa de Jasón!

Coro 4 - ¡Destruida por las tribus de las misiones! ${ }^{9}$

A la vez, nos adelantan el final trágico del derrotero iniciado por Medea y Jasón diez años atrás:

Coro 1 - ¡Este es el lugar y el sitio exacto que se ha elegido para consumar el acto final!

Coro 2 - ¡Te ayudaremos Medea!

Coro 3 - ¡No, no te ayudaremos! (Carcajada).

Coro 4 - ¡Te empujaremos!

Coro 5 - ¡Hoy darás fin al trabajo que comenzaste al salir de tus tierras de la mano de Jasón! ¡Hoy finalizará el gran mal que has arrastrado gloriosa por toda la comarca!

Coro 6 - ¡Nos escucharás y no nos escucharás, según palpite tu corazón de fiera! ${ }^{10}$

\footnotetext{
${ }^{7}$ Médici e Iñiguez 1987: 1.

${ }^{8}$ Médici e Iñiguez 1987: 1.

${ }^{9}$ Médici e Iñiguez 1987: 1.

${ }^{10}$ Médici e Iñiguez 1987: 2.
} 
Se reúnen en ese lugar con un objetivo prefijado: cumplir el destino de los protagonistas.

La relevancia del coro en Una Hoguera en las Tinieblas radica en su naturaleza divina, pues son espíritus telúricos: "Son espíritus de la tierra, errantes, unas veces a favor del bien y otras del mal"11.

$\mathrm{Su}$ atributo de "errantes" hace pensar tanto en el vagar en el territorio como en la errancia en la conducta, a veces favorable, a veces funesta. La gradación en cada intervención de los coreutas manifiesta la índole de estas fuerzas naturales.

En la cultura guaraní, los espíritus provenientes de muertos y animales son nocivos y están condenados a vagar y reencarnarse. El espíritu animal asalta al sujeto al momento de su nacimiento, y constituye, junto con el de origen sagrado, la naturaleza del hombre ${ }^{12}$. El guaraní se siente frágil e influenciable pues ambos espíritus luchan por controlarlo ${ }^{13}$.

En tal sentido, Perla Zayas de Lima, en su obra El universo mítico de los argentinos en escena, habla de la supervivencia de creencias religiosas de las culturas americanas en el teatro argentino. De todas las que menciona, nos interesa aquella sobre la naturaleza de los dioses, puesto que son considerados espíritus malos y conviene aplacarlos ${ }^{14}$.

Por el contrario, la relación connatural entre el coro y Medea no atenúa sus ataques y la vuelve vulnerable:

Coro 3 - ¿Por qué tenías que aguardarlo todo el día con las piernas abiertas? Coro 4 - ¿Por qué tuviste que confiarle los secretos de tu tribu, para que él tomara el poder? $?^{15}$

Medea - ¡Pero yo no tengo la culpa! La culpa es de este amor que me arrastra y me vuelve loca y que me da terror perder. (Levanta la voz con rabia) ¡Hay algo sucio en esta noche que no quiero comprender! ${ }^{16}$

La locura, al igual que todo lo pernicioso, proviene de Añá (el espíritu que representa el mal y se identifica con el jaguar-demonio) y es condenada en la cultura guaraní. Cuando el hombre guaraní enloquece, se transforma en yaguareté-avá: hombre tigre ${ }^{17}$.

Los dramaturgos confieren al coro un papel central en esta tragedia: es el encargado de llevar adelante la acción dramática, actúa como catalizador

\footnotetext{
${ }^{11}$ Médici e Iñiguez 1987: 1.

${ }^{12}$ AA. VV. 1985: 15.

${ }^{13}$ AA. VV. 1985: 15.

${ }^{14}$ Zayas de Lima 2010: 56.

${ }^{15}$ Médici e Iñiguez 1987: 9.

${ }^{16}$ Médici e Iñiguez 1987: 5.

${ }^{17}$ AA.VV. 1985: 17.
} 
incitando a Medea a la venganza: "Serán los interlocutores de los protagonistas, conductores y desencadenantes de la tragedia" ${ }^{18}$.

En la tragedia ática, el coro es el personaje colectivo y anónimo cuyo papel es expresar con sus temores, sus esperanzas y sus juicios los sentimientos de los espectadores, que componen la comunidad cívica ${ }^{19}$. Aristóteles (Poética 1456a 26-27) le da la función de un actor más, participa de la acción pero no decide; es el héroe el que desempeña ese papel.

En la obra correntina, pierde el anonimato y no expresa los sentimientos de los espectadores. Por el contrario, los coreutas empujan, obligan a la protagonista a cometer los crímenes.

Coro 5 - (irá levantando el tono de voz) ¡Venganza!

Coro 6 - ¡Venganza! ¡Venganza!

Coro 1 - ¡Muerte y venganza!

Coro 2 - ¡Suelta tu odio Medea! ${ }^{20}$

E1 diseño lumínico y el sonido dirigen la atención del espectador hacia el coro. La combinación de sonido y silencio, luz y oscuridad ${ }^{21}$ marca la oposición entre dos culturas: la del blanco y la guaraní, y dos dimensiones: la humana y la espiritual ${ }^{22}$. Sólo la vieja y Medea, dada la relación cultural que tienen con el coro, pueden escucharlo:

Medea - ¡Silencio! ¡Ah fuego, no envenenes mi oído! (El coro se repliega formando escenografía. Entra la vieja, especie de aya y nodriza, un poco más pobre que Medea, si es posible) (...)

Vieja - ¡Yo también he consultado al fuego y he escuchado voces!... ${ }^{23}$

La percepción de las voces separa dos culturas puesto que los personajes que representan la del hombre blanco, como Jasón, Creonte y el peón, no perciben siquiera su presencia. Por otra parte, también marca dos dimensiones: la profana y la sagrada, de la que Medea, por ser una hechicera guaraní y estar relacionada con Añá, es la única que puede participar.

La comunicación íntima entre Medea y el coro se da a través del fuego "familiar y tribal a la vez". En comunión con él, revela sus pensamientos y miedos, pero, al mismo tiempo, se reencuentra con sus raíces.

No pueden separarse, en este contexto cultural, lo familiar y lo tribal: el

\footnotetext{
${ }^{18}$ Médici e Iñiguez 1987:1.

${ }^{19}$ Vernant y Vidal-Naquet 1987: 18.

${ }^{20}$ Médici e Iñiguez 1987: 9.

${ }^{21}$ Trastoy y Zayas de Lima 2006:186.

${ }^{22}$ Trastoy y Zayas de Lima 2006: 204.

${ }^{23}$ Médici e Iñiguez 1987: 3-4.
} 
individuo está integrado a la comunidad, por eso Medea no podrá seguir escindida, deberá reunirse nuevamente con su pueblo en comunión en ese fuego tribal.

Medea - (...) ¡Pero esta noche, hermanos míos, espíritus de mi raza, mal definitivo... soy tuya!... ¡Mal... apodérate de mí, hazme por fin tu mujer!... ¡Crímenes oscuros de la noche, acudan en mi ayuda!... ¡Preparen una gran unión entre Medea y la venganza... pero que sea gigante... para que a luz de un mal tan perverso, su sombra oscurezca la tierra ${ }^{24}$.

La luz azulada que baña el escenario deja al coro en penumbras mientras los otros personajes dialogan, lo separa de la esfera humana. En tanto que la proximidad a la luz roja del fuego acontece para provocar la peripecia: se tiñe con la luz roja del fuego tribal cada vez que se acerca a Medea para atormentarla.

Poco a poco esta barrera lumínica se pierde, el coro se aleja cada vez menos de Medea y del fuego, al tiempo que en el texto dramático se van mezclando las intervenciones de unos y otros hasta quedar confundidas en un diálogo rápido al modo del diálogo estíquico antiguo - formando una sola voz.

La luz del fuego recorta el espacio escénico y lo divide en dos: el color rojo, que se identifica con el mundo interior y sagrado de Medea, y el color azul, identificado con el exterior y la esfera humana.

Medea sucumbe a los espíritus animales, pare el odio "un mitaí cambá”25 (niño negro) y lo acuna, imagen contrastante con lo que hace con sus propios hijos.

Una vez consumada la venganza, el coro la rodea y revela la reunión final de Medea con sus dioses telúricos: "Coro 1: ¡Se hundió en la tierra!" . ${ }^{26}$ Es un descenso que la devuelve a sus orígenes, la reúne con Añá. De este modo, Médici e Iñiguez resuelven el deus ex machina de la tragedia de Eurípides.

Desaparecida Medea, nuevamente el coro concentra la atención del público. Sólo quedan en escena los seis coreutas que salen lentamente, en una suerte de éxodo, recitando:

Se escucha el texto siguiente: Coro - Ella está habitando ahora con su padre Añá, ella se desposó definitivamente con Mbae Poché, con la tierra y con la selva. Medea volvió a los infiernos. (Las voces se van perdiendo en la lejanía) ${ }^{27}$.

La conjunción de los elementos en escena que atraen la atención del espectador, tales como el sonido combinado con el silencio, la luz contrastada con la oscuridad, la iluminación en rojo y azul, el poseer o no poseer máscara, destacan

\footnotetext{
${ }^{24}$ Médici e Iñiguez 1987: 28.

${ }^{25}$ Médici e Iñiguez 1987: 8.

${ }^{26}$ Médici e Iñiguez 1987: 32.

${ }^{27}$ Médici e Iñiguez 1987: 32.
} 
la función de agente de la acción dramática del coro a través de la concentración de lenguajes escénicos; al tiempo que señalan la oposición entre las dos culturas.

\section{Conclusión}

La versión libre de Medea de Eurípides escrita por Médici e Iñiguez mantiene del hipotexto el género, el mito, los personajes y sus funciones; pero sitúa la acción en Corrientes, en 1817, en un momento de la historia de la provincia que se caracterizó por la conformación de esa sociedad. En ese contexto histórico y cultural, Medea es una princesa bárbara guaraní, Jasón un criollo, Creonte un caudillo y el coro, los animales salvajes del monte.

Por el carácter sagrado de los seis espíritus telúricos animales de la cultura guaraní que representan los coreutas, la función de este coro tiene otro matiz que no tenía el de la tragedia ática. En Una Hoguera en las Tinieblas, lleva adelante y desencadena la acción porque tiene el poder que Añá le dio. Hostiga a Medea hasta que sucumbe y consuma la venganza.

El coro completa y acentúa la imagen de Medea como bárbara y "bruja". Así, deja entrever la imagen del aborigen que los autores, ubicados en su contexto de producción, configuraron. Desde la perspectiva de éstos, el guaraní es un "otro" enfrentado e inaprehensible: un ser natural, pero en su faceta "salvaje", cuya cultura es apreciada como peligrosa porque implica la posesión de poderes secretos, encaminados a producir el mal, es decir, alteraciones en el orden social dominante.

Los elementos escénicos que el coro reúne a su alrededor (su coreografía, el sonido, la iluminación, el vestuario) modalizan la situación dramática concentrando la atención del espectador. Simultáneamente, delimitan el espacio escénico y simbólico en dos: la cultura del blanco y la guaraní; la dimensión humana y la sagrada.

Médici e Iñiguez otorgan al coro una libertad y un protagonismo en la acción que no tenía en el hipotexto. 


\section{Bibliografía}

Aristóteles (2004), Poética, trad. Sinnott, E. Buenos Aires: Colihue Clásica.

AA. VV. (1985), "Corrientes en el mundo guaranítico", cap. 3, in Separata de Todo es Historia. Buenos Aires: Academia Nacional de la Historia.

Carlson, M. (2009), El teatro como máquina de la memoria. Los fantasmas de la escena. Buenos Aires: Artes del Sur.

Dubatti, J. (1999), El Teatro Laberinto. Ensayos sobre Teatro Argentino. Buenos Aires: Atuel.

Euripide (1965), Médée. Tomo 1. Paris: Les Belles Lettres.

Franco Carvalhal, T. (1996), Literatura Comparada. Buenos Aires: Corregidor.

Genette, G. (1989), Palimpsestos. La Literatura en segundo grado. Madrid: Taurus.

Hardwick, L. (2003), Reception studies. Oxford: University Press.

Médici, J. M., Iñiguez, A. (1987), Una Hoguera en las Tinieblas. Mecanografiada.

Pavis, P. (2000), Elanálisis de los espectáculos. Teatro, mimo, danza, cine. Barcelona: Paidós.

Trastoy, B., Zayas de Lima, P. (2006), Lenguajes escénicos. Buenos Aires: Prometeo.

Vernant, J. P., Vidal-Naquet, P. (1987), Mito y tragedia en la Grecia antigua. Vol. I. Madrid: Paidós.

Zayas de Lima, P. (2010), El universo mítico de los argentinos en escena. Tomo II. Buenos Aires: CELCIT. 